Mini Review

\title{
Considerations on autologous blood transfusion
}

\section{Introduction}

Several strategies exist regarding blood donation and transfusion in preoperative period. These strategies include autologous preoperative donation, normovolemic hemodilution, cell saver, and heterogenic transfusion. We always consider the criteria for blood donation, taking present the type of surgery, preoperative patient condition, and likelihood and amount of bleeding. The American Association of Blood Banks (AABB) Standards for Blood Banks and Transfusion Services requires that the donor-patient's hemoglobin $(\mathrm{Hb})$ be no less than $11 \mathrm{~g} / \mathrm{dL}$ or the hematocrit (Hct) be less than $33 \%$ before each donation. ${ }^{1}$

\section{Autologous donation}

Indications and patients selection for autologous blood donation (AD): Patients undergoing elective surgery may donate preoperatively if the propability of bleeding is high. There are no age or weight limits. Patients may donate $10.5 \mathrm{~mL} / \mathrm{kg}$, in addition to testing samples. Donations may be scheduled more than once a week, but the last should occur no less than 72 hours before surgery to allow time for restoration of intravascular volume. Candidates for preoperative collection should be stable patients scheduled for surgical procedures in which blood transfusion is likely. The most common surgical procedures that probably required transfusion are major orthopedic procedures, vascular surgery, cardiac or thoracic surgery, and radical prostatectomy. ${ }^{2}$ When the transfusion is not likely (less than $10 \%$ ) the use of preoperative blood collection is not recommended. Those cases include cholecystectomy, herniorrhaphy, vaginal hysterectomy, and uncomplicated obstetric delivery. ${ }^{3}$

Contraindications of autologous blood donation: The contraindications of autologous blood transfusion are summarized in Table 1. In the patients with cardiac current diseases, the risks that are associated with autologous blood donation ${ }^{4}$ in these patients are greater than estimated current risks of allogeneic transfusion. ${ }^{5,6}$ The autologous blood donation from pregnant women is not recommended, ${ }^{7}$ because blood is so seldom needed. AD can be considered for women with alloantibodies to multiple or high-incidence antigens or with placenta previa or other conditions placing them at high risk for antepartum or intrapartum hemorrhage. ${ }^{8}$ AABB Standards no longer permit allogeneic transfusion of unused autologous units ("crossover") because autologous donors are not, in the strictest sense, volunteer donors. That experience concorde with our experience.

Aggressive phlebotomy vs. Standard phlebotomy: If the erythropoietic process does not respond to blood phlebotomy in order to maintain the patient's hematocrit level during the donation interval, the donation may be harmful ${ }^{9}$ causing preoperative anemia and an increased possibility of allogeneic blood transfusion. "Aggressive" autologous blood phlebotomy means donation twice weekly for 3 weeks, beginning 25 to 35 days before surgery. The endogenous erythropoietin levels will increase, along with enhanced erythropoiesis representing RBC volume expansion of $19 \%$ to $26 \%$ (Table 2). Exogenous erythropoietin (Eprex) therapy can further stimulate erythropoiesis (up to $50 \%$ RBC volume expansion. ${ }^{10-17}$ Preoperative use of erythropoietin is approved for anemic (Hct<39\%) patients scheduled for no cardiac, nonvascular surgeries.
Volume 6 Issue 2 - 2016

\author{
Arber Jano, Hektor Sula, Rudin Domi \\ Department of Surgery, Service of Anesthesiology and Intensive \\ Care Medicine, "Mother Teresa" University Hospital Center, \\ Albania
}

Correspondence: Rudin Domi,Associate Professor of Anesthesiology, Attending Anesthesiologist-Intensivist, Department of Anesthesiology and Intensive Care, "Mother Teresa" University Hospital Center Tirana,Albania, Tel 00355682067003, Email rdomi73@yahoo.it

Received: October 26, 2016 | Published: November 25, 2016

Advantages and Disadvantages of Autologous Blood Donation: Table 3 summarizes the advantages and disadvantages of autologous donation. Although autologous blood collections have become popular, the costs associated with their collection are higher than those associated with the collection of allogeneic blood.

Normovolemic hemodilution: Normovolemic hemodilution $(\mathrm{NH})$ is the removal of whole blood from a patient while restoring the circulating blood volume with an acellular fluid shortly before an anticipated significant surgical blood loss. $\mathrm{NH}$ relies on the premise that if the concentration of red blood cells is decreased total red cell loss is reduced when large amounts of blood are shed; meanwhile the cardiac output remains normal because intravascular volume is maintained. Decisions about NH should be based on the surgical procedure and on the patient's preoperative blood volume and hematocrit, target hemodilution hematocrit, and other physiologic variables (Table 4).

Table I Contraindications of autologous blood donation

Evidence of infection and risk of bacteremia

Scheduled surgery to correct aortic stenosis

Unstable angina

Active seizure disorder

Myocardial infarction or cerebrovascular accident within 6 months of donation

Patients with significant cardiac or pulmonary disease who have not yet been cleared

High-grade left main coronary artery disease

Cyanotic heart disease

Uncontrolled hypertension

The blood is then stored at room temperature and reinfused during surgery after major blood loss has ceased, or sooner if indicated. Simultaneous infusions of crystalloid $(3 \mathrm{~mL}$ crystalloid for each $1 \mathrm{~mL}$ of blood withdrawn) and colloid (dextrans, starches, gelatin, albumin [ $1 \mathrm{~mL}$ for each $1 \mathrm{~mL}$ of blood withdrawn]) have been recommended. ${ }^{18}$ Blood must be collected in an aseptic manner, ordinarily into standard blood collection bags with citrate anticoagulant. Units must be 
properly labeled and stored. The label must contain, at a minimum, the patient's full name, medical record number, date and time of collection, and the statement "For Autologous Use Only." Room temperature storage should not exceed 8 hours. All of these studies found $\mathrm{NH}$ to be equivalent to $\mathrm{AD}$ in eliminating the need for allogenic blood transfusions and suggest that $\mathrm{NH}$ and $\mathrm{AD}$ are equivalent for avoiding allogenic blood transfusions during elective surgery. ${ }^{19}$ Longterm outcomes including anesthesia and surgery times, intraoperative hemodynamic values, and length of hospital stays were also equivalent in $\mathrm{AD}$ and $\mathrm{NH}$, but $\mathrm{NH}$ is much less costly than $\mathrm{AD} .^{19,20}$

Table 2 Endogenous erythropoietin-mediated erythropoiesis

\begin{tabular}{|c|c|c|c|c|c|c|}
\hline & \multirow[t]{2}{*}{ Patients (n) } & \multicolumn{2}{|l|}{ RBC (mL) } & \multicolumn{2}{|l|}{ Net RBC } & \multirow{2}{*}{ Ref } \\
\hline & & Removed (Donated) & Produced & Expansion (\%) & Iron therapy & \\
\hline \multirow{4}{*}{ Standard Phlebotomy } & 108 & 522 & 351 & 19 & PO & 13 \\
\hline & 22 & 590 & 220 & II & None & 14 \\
\hline & 45 & 621 & 331 & 17 & $\mathrm{PO}$ & 14 \\
\hline & 41 & 603 & 315 & 16 & PO, IV & 14 \\
\hline \multirow{5}{*}{ Aggressive Phlebotomy } & 30 & 540 & 397 & 19 & None & 14 \\
\hline & 30 & 558 & 473 & 23 & $\mathrm{PO}$ & 14 \\
\hline & 30 & 522 & 436 & 21 & IV & 14 \\
\hline & 24 & 683 & 568 & 26 & $\mathrm{PO}$ & 15,16 \\
\hline & 23 & 757 & 440 & 19 & $\mathrm{PO}$ & 17 \\
\hline
\end{tabular}

Table 3 Advantages and disadvantages of autologous blood donation

\begin{tabular}{ll}
\hline Advantages & Disadvantages \\
\hline Prevents transmitted disease & Does not affect risk of bacterial contamination \\
Prevents red cell alloimmunization & Does not affect risk of ABO incompatibility error \\
Supplements the blood supply & Is more costly than allogeneic blood \\
Provides compatible blood for patients & Results in wastage of blood not transfused with alloantibodies \\
Prevents adverse transfusion reactions & Increased incidence of adverse reactions to autologous donation \\
Provides reassurance to patients concerned about blood risks & Subjects patient to perioperative anemia and increased likelihood of transfusion
\end{tabular}

Table 4 Criteria for selection of patients for normovolemic hemodilution

Likelihood of transfusion exceeds $10 \%$ (i.e., blood requested for crossmatch according to a maximum surgical blood order schedule)

Preoperative hemoglobin level of at least $12 \mathrm{~g} / \mathrm{dL}$

Absence of clinically significant coronary, pulmonary, renal, or liver disease

Absence of severe hypertension

Absence of infection and risk of bacteremia

\section{Acknowledgments}

None.

\section{Conflicts of interest}

The authors declare there are no conflicts of interest.

\section{Funding}

None.

\section{References}

1. American Association of Blood Banks. Standards for Blood Banks and Transfusion Services. 21st ed. USA: Bethesda, American Association of Blood Banks; 2002.

2. Goodnough LT. Preoperative autologous donation. In: Spence RK editor. Problems in General Surgery. USA: Lippincott Williams \& Wilkins, Philadelphia; 2000:25-31.

3. Renner SW, Howanitz PJ, Bachner P. Preoperative autologous blood donation in 612 hospitals. Arch Pathol Lab Med. 1992;116(6):613-619.

4. Popovsky MA, Whitaker B, Arnold NL. Severe outcomes of allogeneic and autologous blood donation: Frequency and characterization. Transfusion. 1995;35(9):734-737.

5. Goodnough LT, Shander A, Brecher ME. Transfusion medicine: Looking toward the future. Lancet. 2003;361(9352):161-169.
6. Goodnough LT, Brecher ME, Kanter MH, et al. Medical progress: Transfusion medicine. Part I. Blood transfusion. $N$ Engl J Med. 1999;340:439-447.

7. Sayers MH. Controversies in transfusion medicine: Autologous blood donation in pregnancy. Con Transfusion. 1990;30(2):172-174.

8. Kanter MH, Van Maanen D, Anders KH, et al. Preoperative autologous blood donation before elective hysterectomy. JAMA. 1996;276(10):798801

9. Cohen JA, Brecher ME. Preoperative autologous blood donation: Benefit or detriment? A mathematical analysis. Transfusion. 1995;35(8):640644

10. Goodnough LT, Rudnick S, Price TH, et al. Increased preoperative collection of autologous blood with recombinant human erythropoietin therapy. N Engl J Med. 1989;321(17):1163-1167.

11. Goodnough LT, Price TH, Rudnick S. Preoperative red blood cell production in patients undergoing aggressive autologous blood phlebotomy with and without erythropoietin therapy. Transfusion. 1992;32(5):441-445.

12. Goodnough LT, Price TH, Friedman KD, et al. A phase III trial of recombinant human erythropoietin therapy in non-anemic orthopedic patients subjected to aggressive autologous blood phlebotomy: Dose, response, toxicity, efficacy. Transfusion. 1994;34(1):66-71.

13. Goodnough LT, Bravo J, Hsueh Y, et al. Red blood cell volume in autologous and homologous units: Implications for risk/benefit assessment for autologous blood "crossover" and directed blood transfusion. Transfusion. 1989;29(9):821-822. 
14. Brecher ME, Rosenfeld M. Mathematical and computer modeling of acute normovolemic hemodilution. Transfusion. 1994;34(2):176-179.

15. Weiskopf RB. Mathematical analysis of isovolemic hemodilution indicates that it can decrease the need for allogeneic blood transfusion. Transfusion. 1995;35(1):37-41.

16. Petry AF, Jost T, Sievers H. Reduction of homologous blood requirements by blood pooling at the onset of cardiopulmonary bypass. J Thorac Cardiovasc Surg. 1994;107(5):1210-1214.

17. Monk TG, Goodnough LT, Brecher ME. A prospective, randomized trial of three blood conservation strategies for radical prostatectomy. Anesthesiology. 1999;91:24
18. Goodnough LT, Brecher ME, Monk TG. Acute normovolemic hemodilution in surgery. Hematology. 1992;2:413.

19. Monk TG. Is Acute Normovolemic Hemodilution Cost Effective. In: Fleisher LA, editor. Evidence-Based Practice of Anesthesiology. Saunders, Philadelphia, USA; 2004:205-209.

20. National strategy for safe blood transfusion, National Blood Center, University Military Hospital Center, 2003. 